\title{
EHMTI-0129. 3D-cinema and headache: preliminary results of a prospective cross- sectional study
}

\author{
M Braschinsky ${ }^{* *}$, A Rakitin ${ }^{1}$, N Zmachinskaja², O Zukovskaja², B Saar², A Karask², L Sabre \\ From 4th European Headache and Migraine Trust International Congress: EHMTIC 2014 \\ Copenhagen, Denmark. 18-21 September 2014
}

\section{Introduction}

3D-cinema is a growing audio-visual experience worldwide. There are anecdotal reports, that the exposure to 3D-movies can induce headache.

\section{Aim}

To establish the frequency of occurrence of headache after viewing $3 \mathrm{D}$-movies in commercial cinemas, to describe the headache characteristics in response to the exposure and to assess possible contributing co-factors.

\section{Methods}

Specifically designed questionnaire, containing demographic data, name of a movie, prior history of headaches, exposure to possible contributing co-factors and headache descriptors, was distributed to 6000 visitors of three major cinemas in Estonia.

\section{Results}

By the date of the abstract's submission 1131 persons (337 men and 794 women) have responded to the questionnaire. The mean age of responders was 33 years (6-74). Among them $26.6 \%$ reported to have had a headache in response to work in front of a non-3D computer screen, $13.9 \%$ in relation to $3 \mathrm{D}$ movies, and only $1.5 \%$ after watching $2 \mathrm{D}$-films earlier in life. In this study, however, $6.2 \%$ of men and $11.6 \%$ of women reported to have headache: women were at a higher risk of occurrence of headache after or during the 3D-cinema compared to men $(\mathrm{OR}=1.78 ; 95 \% \mathrm{CI}=1.18-2.69)$. More specific and final results, including the subgroups analysis will be presented.

${ }^{1}$ Neurology Clinic, Tartu University Hospital, Tartu, Estonia

Full list of author information is available at the end of the article

\section{Conclusions}

Watching 3D-movies at a cinema can cause a headache. Further studies are needed to confirm the possible risk factors of individual susceptibility to the 3D-cinema headache. There is a need of rising public awareness of possible discomfort people may suffer during and after the explosion to 3D-movies.

No conflict of interest.

\section{Authors' details}

${ }^{1}$ Neurology Clinic, Tartu University Hospital, Tartu, Estonia. ${ }^{2}$ Faculty of Medicine, Tartu University, Tartu, Estonia.

Published: 18 September 2014

doi:10.1186/1129-2377-15-S1-C8

Cite this article as: Braschinsky et al.: EHMTI-0129. 3D-cinema and

headache: preliminary results of a prospective cross-sectional study.

The Journal of Headache and Pain 2014 15(Suppl 1):C8.

Submit your manuscript to a SpringerOpen ${ }^{\bullet}$ journal and benefit from:

- Convenient online submission

- Rigorous peer review

- Immediate publication on acceptance

- Open access: articles freely available online

- High visibility within the field

- Retaining the copyright to your article

Submit your next manuscript at $\gg$ springeropen.com (c) 2014 Braschinsky et al; licensee Springer. This is an Open Access article distributed under the terms of the Creative Commons Attribution License (http://creativecommons.org/licenses/by/2.0), which permits unrestricted use, distribution, and reproduction in any medium, provided the original work is properly cited. 